\title{
Retrospective review of pediatric and adult autoimmune hepatitis in two quaternary care centres in British Columbia: Increased prevalence seen in British Columbia's First Nations community
}

\author{
Henry V Chung MD FRCPC ${ }^{1 *}$, Mark Riley MD FRCPC ${ }^{2 *}$, Jin $\mathrm{K} \mathrm{Ho} \mathrm{MB} \mathrm{FRCPC}^{1 *}$, Benjamin Leung $\mathrm{MD}^{3}$, \\ Gareth P Jevon MB BCh FRCPC ${ }^{4}$, Laura T Arbour MD FRCPC FCCMG ${ }^{5}$, Colin Barker MSC MD FRCPC ${ }^{2}$, \\ Richard Schreiber MD FRCPC ${ }^{2}$, Eric M Yoshida MD MHSc FRCPC ${ }^{1,6}$
}

\begin{abstract}
HV Chung, M Riley, JK Ho, et al. Retrospective review of pediatric and adult autoimmune hepatitis in two quaternary care centres in British Columbia: Increased prevalence seen in British Columbia's First Nations community. Can J Gastroenterol 2007;21(9):565-568.
\end{abstract}

BACKGROUND: It has been previously reported that British Columbia's (BC's) First Nations (Aboriginal) community has an increased risk of autoimmune diseases, including rheumatological conditions (rheumatoid arthritis, systemic lupus) and primary biliary cirrhosis. The researchers hypothesized that this community may also be at increased risk for autoimmune hepatitis (AIH).

METHODS: Independent, retrospective reviews of the databases of two separate tertiary/quaternary British Columbia universityaffiliated health care institutions, the Adult Liver Transplant Program of the BC Transplant Society and the Division of Pediatric Gastroenterology, BC Children's Hospital (Vancouver, BC), were performed. All patients referred with a diagnosis of probable or definite AIH who identified themselves as being of First Nations descent from 1988 to 2004 were reviewed. The liver transplant database records all adult patients in the province referred for transplant assessment. The pediatric database records all children referred to the BC Children's Hospital.

RESULTS: A total of 68 adult patients with a definite or probable diagnosis of $\mathrm{AIH}$ were referred to the liver transplant program. Twelve patients (17.6\%) were Aboriginal, 11 of which were female. Similarly, a total of 30 children with probable or definite AIH were identified from the pediatric database. Six of these cases (20\%) were identified in Aboriginal children.

CONCLUSIONS: The findings suggest an increased prevalence of AIH among BC's First Nations community. A disproportionate First Nations representation was found on independent review of two databases. Future studies are needed to determine the true prevalence of AIH in this community, and to uncover the genetic predisposition and the environmental triggers explaining this phenomenon.

Key Words: Aboriginal; Adult; Autoimmune hepatitis; First Nations; Pediatric
Une analyse rétrospective de l'hépatite autoimmune chez les enfants et les adultes dans deux centres de soins quaternaires de la Colombie-Britannique : Une plus forte prévalence au sein d'une communauté des Premières nations de la Colombie-Britannique

HISTORIQUE : Il a déjà été déclaré que la communauté des Premières nations (autochtones) de la Colombie-Britannique (CB) est plus vulnérable aux maladies auto-immunes, y compris les troubles rhumatologiques (polyarthrite rhumatoïde, lupus systémique) et la cirrhose hypertrophique de Hanot-Gilbert. Les chercheurs ont postulé que cette communauté serait peut-être également plus à risque d'hépatite autoimmune (HAI).

MÉTHODOLOGIE : On a procédé à des analyses rétrospectives indépendantes des bases de données de deux établissements de santé tertiaires et quaternaires affiliés à des universités de la CB, le programme de greffe du foie de la BC Transplant Society et l'unité de gastroentérologie pédiatrique du BC Children's Hospital (Vancouver, CB). Tous les patients aiguillés en raison d'un diagnostic d'HAI probable ou définitif entre 1988 et 2004 et qui avaient précisé être issus des Premières nations ont fait l'objet de l'analyse. La base de données des greffes du foie contient le registre de tous les patients adultes de la province aiguillés pour subir une évaluation en vue d'une greffe. La base de données pédiatrique contient le registre de tous les enfants aiguillés vers le BC Children's Hospital.

RÉSULTATS : Au total, 68 patients adultes présentant un diagnostic probable ou définitif d'HAI ont été aiguillés vers le programme de greffe du foie. Douze patients (17,6\%) étaient autochtones, et 11 étaient des femmes. De même, on a repéré 30 enfants présentant un diagnostic probable ou définitif d'HAI dans la base de données pédiatriques. Six de ces cas (20\%) étaient des enfants autochtones.

CONCLUSIONS : Les observations laissent supposer une prévalence plus élevée d'HAI au sein de la communauté des Premières nations de la CB. On a constaté une représentation disproportionnée des Premières nations dans une analyse indépendante de deux bases de données. Il faudra mener d'autres études pour déterminer la véritable prévalence d'HAI au sein de cette communauté et établir la prédisposition génétique et les déclencheurs environnementaux qui expliquent ce phénomène.

*Primary authors of equal significance

${ }^{1}$ Division of Gastroenterology, Department of Medicine; ${ }^{2}$ Department of Pediatrics; ${ }^{3}$ Department of Medicine; ${ }^{4}$ Department of Pathology;

${ }^{5}$ Department of Medical Genetics, University of British Columbia; ${ }^{6}$ British Columbia Transplant Society, Vancouver, British Columbia

Correspondence: Dr Eric M Yoshida, Division of Gastroenterology, Vancouver General Hospital, Diamond Health Care Centre,

Suite \#5153 - 2775 Laurel Street, Vancouver, British Columbia V5Z 1M9. Telephone 604-875-5371, fax 604-875-5373,

e-mail eric.yoshida@vch.ca

Received for publication September 18, 2006. Accepted December 5, 2006 
T here are currently 3,868,875 residents of British Columbia (BC), and of those, 170,025 people have identified themselves as Aboriginal or First Nations on the 2001 BC Census, representing $4.4 \%$ of BC's population (1). This community has a disproportionately high mortality rate from chronic liver diseases (2); however, it is difficult to ascertain the etiology of the liver disease, because National Vital Statistics has previously collected all deaths from chronic liver disease under the category 'alcohol-related' or under a separate category of 'digestive diseases' (3). It has been previously reported that this population has a higher incidence of rheumatological diseases (4-7). We subsequently reported that this population also suffers from a high prevalence of primary biliary cirrhosis (PBC) $(8,9)$. Because it is believed that the autoimmune liver diseases, specifically PBC and autoimmune hepatitis (AIH), share many epidemiological and clinical characteristics, we hypothesized that this population would also be at an increased risk for AIH $(10,11)$ in the province of BC.

\section{METHODS}

An independent review of the databases of two separate tertiary/quaternary university-affiliated health care institutions in Vancouver, BC, was performed. The database reviews were independent projects conducted by clinicians associated with the two institutions (BC Transplant Society [BCTS]: HVC, JKH, BL, LTA and EMY; and the BC Children's Hospital [BCCH]: MR, GPJ, $\mathrm{CB}$ and RS) but are reported together in this paper:

\section{Study associated with the BCTS}

The Adult Liver Transplant Referral Database of the BCTS, an agency of the Provincial Health Services Authority of BC that administrates all aspects of solid organ transplantation in BC, was retrospectively reviewed. This database includes all patients older than 18 years of age in $\mathrm{BC}$ referred for liver transplant assessment. The database includes both demographic information of referred patients and clinical information, including etiology of end-stage liver disease. A classification of $\mathrm{AIH}$ is based on clinical information provided by referring physicians and further investigations initiated by the BCTS. Clinical information supporting a database classification of AIH includes: negative viral hepatitis markers (specifically hepatitis B and C); the absence of any other possible etiology, including alcoholic liver disease; seropositivity for antinuclear antibodies and anti-smooth muscle antibodies; and liver biopsies consistent with a diagnosis of AIH, if available. Although the BCTS database predates the International Autoimmune Hepatitis Score (12), the estimated score of patients classified with AIH was at least 10 ("probable AIH" [12]). All patients referred with a diagnosis of probable or definite AIH who identified themselves as First Nations or of Aboriginal descent from 1988 to 2004 were reviewed.

\section{Study associated with the $\mathrm{BCCH}$}

A retrospective review was performed of all children up to 19 years of age diagnosed with immune liver disease between 1992 and 2004 at the BCCH, a quaternary care referral centre for the province of $\mathrm{BC}$. The diagnoses of immune liver disease were based on a detailed family history of all patients at the time of initial consultation, with supportive laboratory investigations and liver biopsy pathology. All liver biopsies were interpreted by a single pathologist to review the initial liver biopsies from each case. A detailed family history of all patients with immune liver disease was taken at the time of initial BCCH consultation.

\section{Statistical analysis}

Statistical analysis consisted of descriptive statistics of both databases. Analytical statistical analysis of the adult liver transplant referral database of the BCTS was performed using a binomial distribution comparing the proportion of Aboriginal people referred with AIH against published 2001 Canada Census data $(1,13)$ of BC's proportion of First Nations people (Statistics Canada). Statistical analysis was performed with the R Project for Statistical Computing (Free Software Foundation Inc, USA) computer software program. The alpha level of significance for a two-tailed test was 0.05 .

The statistical analysis of the BCCH Immune Liver Disease Database was performed using descriptive statistics and twotailed $\chi^{2}$ tests. The estimated prevalence of pediatric AIH was calculated using the 2001 Canada Census data of First Nations children in BC. The statistical analysis of the pediatric database was performed using the STATA 8.0 (StatCorp LP, USA) computer software package.

\section{RESULTS}

\section{Adult Liver Transplant Referral Database review}

A total of 68 patients with a diagnosis of probable or definite AIH were referred to the BCTS for liver transplant assessment. The median age was 45 years. Forty-nine of the patients (72\%) were female. Twelve of these patients (17.6\%) identified themselves as First Nations and 11 of these 12 (92\%) were female. Of the First Nations patients, four patients (33\%) received a liver transplant, four (33\%) died either during assessment or while wait-listed for a transplant, three $(25 \%)$ were deemed unsuitable after transplant assessment and one (8\%) refused transplantation. Of 170,025 First Nations people in BC, 101,710 were 20 years of age or older (of a total BC population of $3,868,875$, or $4.4 \%$ ), a statistically significant difference was found between the proportion of Aboriginal people referred for liver transplant assessment with a diagnosis of $\mathrm{AIH}$ and the proportion of First Nations people in the province (2001 Canada Census [12]) $(P=0.0004)$. We note that the binomial distribution analysis was performed conservatively by comparing the proportion of First Nations patients referred with a diagnosis of $\mathrm{AIH}$ with all First Nations people in BC regardless of age group. The subset of First Nations people in BC older than 19 years of age (ie, 3.5\% of BC's adult population) achieved even greater statistical significance.

\section{Pediatric Immune Liver Disease Database review}

A total of 39 cases of immune liver disease were identified at the BCCH (Table 1$)$. Thirty cases $(76.9 \%)$ of probable or definite AIH were diagnosed. Of these, six definite cases of AIH (20\%) occurred in First Nation's children, and all cases were type 1. Four of the children (67\%) were female and two (33\%) were male; their average age at diagnosis was 10.3 years old. In the non-First Nations children, the average age at diagnosis was 10.9 years. Elevated biochemical values were similar between the two groups at presentation. Liver histology was also similar between these groups (Table 2). The non-AIH group (nine patients) included six cases of primary sclerosing cholangitis that were all associated with inflammatory bowel disease (IBD) and three patients with overlap syndromes (with two associated with IBD). All of these non-AIH cases were in 
TABLE 1

\begin{tabular}{lcc}
$\begin{array}{l}\text { British Columbia Children's Hospital autoimmune } \\
\text { hepatitis (AlH) database: Patient characteristics }\end{array}$ \\
\hline Characteristic & $\begin{array}{c}\text { Non-First Nations } \\
\text { with AlH (n=24) }\end{array}$ & $\begin{array}{c}\text { First Nations } \\
\text { with AlH (n=6) }\end{array}$ \\
\hline Prevalence (0 to 19 years of age) & $2.4 / 100,000$ & $9.9 / 100,000$ \\
Average age at diagnosis (years) & 10.9 & 10.3 \\
Female-to-male ratio, $n$ & $13: 8$ & $4: 2$ \\
Jaundice, $n$ & 11 & 5 \\
Elevated antinuclear antibody titre, $n$ & 21 & 5 \\
Presence of smooth muscle antibody, $n$ & 19 & 4 \\
Other autoimmune disease*, $n$ & 8 & 6 \\
Treatment & & \\
Prednisone & 24 & 4 \\
Azathioprine & 21 & 4 \\
Result, $\mathrm{n}$ & & 3 \\
Remission & 16 & \\
Relapse & 10 & 4 \\
\hline
\end{tabular}

${ }^{*} P=0.0017$, two-sample test of proportion

non-First Nations children. The prevalence of AIH in BC's pediatric population was therefore estimated to be 9.9 per 100,000 people for First Nations children and 2.4 per 100,000 people in non-First Nations children. This represents a fourfold increase in immune liver disease in First Nations children compared with non-First Nations children. Fifty per cent of the First Nations children were also found to have other autoimmune diseases, while only 33\% of non-First Nations children had other autoimmune diseases. All of the First Nations children had a family history of autoimmune diseases, and this was significantly different from the non-First Nations group $(\mathrm{P}=0.0017)$.

\section{DISCUSSION}

$\mathrm{AIH}$ is a chronic hepatitis characterized by necroinflammation of the liver, as well as the presence of autoantibodies and hypergammaglobulinemia in the absence of any other causes (14). It has a female predominance, with a peak incidence between 10 to 30 years of age and then another peak after 40 years of age (11). The etiology of AIH is unknown; however, it is postulated that an environmental agent triggers a T cellmediated response against liver antigens in a genetically susceptible individual (15). There are two major subtypes of AIH. Type 1 is associated with elevated antinuclear antibody, smooth muscle antibody, atypical perinuclear antineutrophil cytoplasmic antibody, and autoantibodies to soluble liver antigen and liver-pancreas antigen (15). Type $2 \mathrm{AIH}$ is characterized by antibodies against liver-kidney microsome-1 and liver cytosol 1 . Type 2 is rare, and tends to occur in younger people and almost exclusively in females $(15,16)$. Immunosuppression with prednisone, azathioprine or 6-mercaptopurine is the mainstay of treatment (17).

Before the Autoimmune Hepatitis Group revised scoring system (12) there was no standardized method of diagnosing AIH. There are also few studies reporting the prevalence of AIH, and only two population-based studies have been published. An often quoted Norwegian study (18) demonstrated a point prevalence of 16.9 per 100,000 people, while in an Alaskan study (19), the prevalence of definite or probable AIH in Alaska Natives (ie, First Nations people) was more
TABLE 2

British Columbia Children's Hospital autoimmune hepatitis database: Histological features

\begin{tabular}{lcc}
\hline Histological feature & Non-First Nations $(\mathbf{n = 1 6 )}$ & First Nations $(\mathbf{n}=\mathbf{6})$ \\
\hline Mean portal grade & 3.12 & 3.50 \\
Mean lobule grade & 1.59 & 1.33 \\
Stage (0-4) & 2.71 & 2.33 \\
Duct inflammation (\%) & 56.00 & 33.00 \\
\hline
\end{tabular}

Liver biopsy scoring system, data from reference 30

than double that at 42.9 per 100,000 people. The disease appears to be relatively uncommon in Asia, but one study reported that African Americans with AIH are more likely than Caucasians to present with advanced disease (20-24). Nevertheless, it appears to be present in diverse ethnic groups in both pediatric and adult populations.

We have previously reported that PBC appears to be common among the First Nations population of BC, has a strong First Nations familial association and appears to be geographically clustered along the Pacific coastal areas $(8,9,25)$. Similar findings of an increased likelihood of PBC in First Nations people has been reported in Alaska (19), which is in close proximity to $\mathrm{BC}$ (ie, Southeast Alaska, also referred to as the 'Alaskan Panhandle'). A demographic study of PBC in Ontario (26) did not reveal a higher than average incidence of $\mathrm{PBC}$ in their First Nations communities; however, it is not clear whether this difference is due to under-recognition of the condition in the First Nations people of Ontario or whether a different genetic ancestry may alter susceptibility compared with BC's First Nations community. Of interest, the Southeast Alaskan Indians, who likely share a common ancestry with the BC First Nations, have been reported to have a high rate of PBC and other autoimmune diseases, suggesting a genetic predisposition; however, it is not clear whether AIH has a similarly high rate in that same area. In $\mathrm{BC}, \mathrm{PBC}$ has a strong familial component (9), consistent with our findings of a strong family history of autoimmune diseases in the pediatric component of our study. It is hypothesized that the increased burden of PBC carried by BC's First Nations community is due to a strong genetic predisposition to autoimmune diseases, combined with exposures to common environmental triggers (9). Our study found that significantly more First Nations children with AIH had a family history of autoimmune disease. Because the BCTS database did not capture family history data, we were unable to draw any similar inferences regarding First Nations adults. However, a recent report of a First Nations mother-daughter pair with PBC and AIH gives support to this hypothesis (27).

In our current study, a disproportionate prevalence of $\mathrm{AIH}$ was found among First Nations adults and children, even though two different populations were studied, ie, an adult liver transplant referral population and a pediatric quaternary care referral population. It is very interesting that the proportions of $\mathrm{AIH}$ in First Nations people were almost identical (17.6\% and $20 \%$ ) in these two databases. The $\mathrm{BCCH}$ is the only pediatric hepatology referral centre in BC, and therefore, our study likely reflects the true prevalence of $\mathrm{AIH}$ in BC's pediatric population. In the BCCH database, we found that First Nations and non-First Nations children had similar age, sex, and clinical and biochemical presentation distributions, as well as similar responses to therapy. Liver biopsy histologies were also very similar in both groups. All First Nations children had 
type 1 AIH (data not shown), and no cases were associated with IBD. Thus, both groups tended to have similar diseases, except that the prevalence of AIH in First Nations children was four times that of non-First Nations children. In contrast to the BCCH AIH database, the BCTS database includes only patients with end-stage cirrhosis, because patients referred to the BCTS are referred specifically for liver transplant assessment. Although no inferences can be made regarding patients who do not have end-stage cirrhosis, the BCTS database, which we acknowledge is subject to the limitations of all quarternary centre databases, does provide a cross-sectional 'snapshot' of the spectrum of end-stage cirrhosis in BC within a defined temporal period and is useful for hypothesis generation, especially because there is no other chronic liver disease registry in the province. Unlike the situation with $\mathrm{PBC}$, in which no unequivocal, definitive cirrhosis-sparing therapy is available, it is well recognized that long-term biochemical and histological remission is possible in AIH (28). The finding that a disproportionate number of First Nations adults have been referred to the BCTS with $\mathrm{AIH}$-associated cirrhosis may reflect late diagnosis and/or lack of early treatment rather than a truly increased prevalence. It is also possible that the prevalence of $\mathrm{AIH}$ in the First Nations community of BC is even higher; many cases may either be misdiagnosed or go unrecognized because the patients may be asymptomatic or only have mild symptoms (17). There may also be many patients who are not referred to

\section{REFERENCES}

1. BC Stats: 2001 census profile - British Columbia. <www.bcstats.gov.bc.ca/data/cen01/profiles/59000000.pdf> Version current at July 16, 2007.

2. British Columbia Vital Statistics Agency: Regional analysis of health statistics for status Indians in British Columbia, 1991-1999 - Birth related and mortality summaries for BC and 20 health regions. <http://www.vs.gov.bc.ca/stats/indian/hrindian/index.html > Version current at July 16, 2007.

3. British Columbia Vital Statistics Agency: Regional analysis of health statistics for status Indians in British Columbia, 1992-2002. $<$ www.vs.gov.bc.ca/stats/indian/index.html $>$. Version current at July 16, 2007.

4. Atkins C, Reuffel L, Roddy J, Platts M, Robinson H, Ward R. Rheumatic disease in the Nuu-Chah-Nulth native Indians of the Pacific Northwest. J Rheumatol 1988;15:684-90.

5. Peschken CA, Esdaile JM. Systemic lupus erythematosus in North American Indians: A population based study. J Rheumatol 2000;27:1884-91.

6. Boyer GS, Templin DW, Lanier AP. Rheumatic diseases in Alaskan Indians of the southeast coast: High prevalence of rheumatoid arthritis and systemic lupus erythematosus. J Rheumatol 1991;18:1477-84.

7. Peschken CA, Esdaile JM. Rheumatic diseases in North America's indigenous peoples. Semin Arthritis Rheum 1999;28:368-91.

8. Yoshida EM, Caron NR, Buczkowski AK, et al. Indications for liver transplantation in British Columbia's Aboriginal population: A 10-year retrospective analysis. Can J Gastroenterol 2000;14:775-9.

9. Arbour L, Rupps R, Field L, et al. Characteristics of primary biliary cirrhosis in British Columbia's First Nations population. Can J Gastroenterol 2005;19:305-10.

10. Kaplan MM. Primary biliary cirrhosis. N Engl J Med 1996;335:1570-80.

11. Feld JJ, Heathcote EJ. Epidemiology of autoimmune liver disease. J Gastroenterol Hepatol 2003;18:1118-28.

12. Alvarez F, Berg PA, Bianchi FB, et al. International Autoimmune Hepatitis Group Report: Review of criteria for diagnosis of autoimmune hepatitis. J Hepatol 1999;31:929-38.

13. Statistics Canada: 2001 Census of Canada. <www12.statcan.ca/English/census01/home/index.cfm>. Version current at July 16, 2007.

14. Czaja A. Autoimmune hepatitis: Evolving concepts and treatment strategies. Dig Dis Sci 1995;40:435-56.

15. Krawitt EL. Autoimmune hepatitis. N Engl J Med 2006;354:54-66.

16. Duchini A, McHutchison JG, Pockros PJ. LKM-positive autoimmune hepatitis in the western United States: A case series. Am J Gastroenterol 2000;95:3238-41. either centre because of stereotypes or biases (29). Regardless, it is clear from our review of the BCTS liver transplant assessment database that further epidemiological studies of AIH in BC's First Nations community are required to determine whether the disproportionate number of First Nations people with end-stage AIH is a result of a truly increased prevalence or because of inadequate diagnosis or treatment of this condition by health care professionals involved with the First Nations community.

\section{CONCLUSIONS}

Our study suggests an increased prevalence of AIH among BC's First Nations community; disproportionate First Nations representation was found on independent review of two databases. Special attention should be paid to this population to identify these patients so that early effective medical care can be provided. Future studies are required to determine the true prevalence of $\mathrm{AIH}$ in this community, as well as to uncover the genetic predisposition and the environmental triggers to explain this phenomenon.

ACKNOWLEDGMENTS AND DISCLOSURES: The authors sincerely thank Dr Nhu Le of the Department of Epidemiology, BC Cancer Agency, for assistance with the statistical analysis. This work was presented at the Canadian Association for the Study of Liver Disease First Annual Conference as two separate poster presentations in March 2005 in Banff, Alberta.

17. Czaja AJ, Freese DK; American Association for the Study of Liver Disease. Diagnosis and treatment of autoimmune hepatitis. Hepatology 2002;36:479-97.

18. Boberg KM, Aadland E, Jahnsen J, Raknerud N, Stiris M, Bell H. Incidence and prevalence of primary biliary cirrhosis, primary sclerosing cholangitis, and autoimmune hepatitis in a Norwegian population. Scand J Gastroenterol 1998;33:99-103.

19. Hurlburt KJ, McMahon BJ, Deubner H, Hsu-Trawinski B, Williams JL, Kowdley KV. Prevalence of autoimmune liver disease in Alaska Natives. Am J Gastroenterol 2002;97:2402-7.

20. Gupta R, Agarwal SR, Jain M, Malhotra V, Sarin SK. Autoimmune hepatitis in the Indian subcontinent: 7 years experience.

J Gastroenterol hepatol 2001;16:1144-8.

21. Gregorio GV, Portmann B, Karani J, et al. Autoimmune hepatitis/ sclerosing cholangitis overlap syndrome in childhood: A 16-year prospective study. Hepatology 2001;33:544-53.

22. Toda G, Zeniya M, Watanabe F, et al. Present status of autoimmune hep atitis in Japan - correlating the characterisitics with international criteria in an area with a high rate of HCV infection. Japanese National Study Group of Autoimmune Hepatitis. J Hepatol 1997;26:1207-12.

23. Lee YM, Teo EK, Ng TM, Khor C, Fock KM. Autoimmune hepatitis in Singapore: A rare syndrome affecting middle-aged women. J Gastroenterol Hepatol 2001;16:1384-9.

24. Lim KN, Casanova RL, Boyer TD, Bruno CJ. Autoimmune hepatitis in African Americans: Presenting features and response to therapy. Am J Gastroenterol 2001;96:3390-4.

25. Arbour L, Field L, Ross P, Erikson A, Yoshida E. The mystery of primary biliary cirrhosis in British Columbia's First Nations people. Int J Circumpolar Health 2004;63(Suppl 2):185-8.

26. Witt-Sullivan H, Heathcote J, Cauch K, et al. The demography of primary biliary cirrhosis in Ontario, Canada. Hepatology 1990;12:98-105.

27. Riley M, Ho JK, Shreiber R, Arbour L, Yoshida EM. PBC and AIH in a First Nations mother daughter pair. Can J Gastroenterol 2005;19:191. (Abst)

28. Johnson PJ, McFarlane IG, Williams R. Azathioprine for long-term maintenance of remission in autoimmune hepatitis. N Engl J Med 1995;333:958-63.

29. Yoshida EM, Riley M, Arbour LT. Autoimmune liver disease and the Canadian First Nations Aboriginal Communities of British Columbia's Pacific Northwest. World J Gastroenterol 2006;12:3625-7.

30. Desmet VJ, Gerber M, Hoofnagle JH, Manns M, Scheuer PJ. Classification of chronic hepatitis: Diagnosis, grading and staging. Hepatology 1994;19:1513-20. 


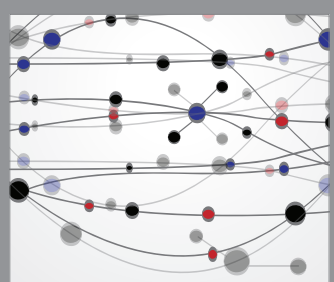

The Scientific World Journal
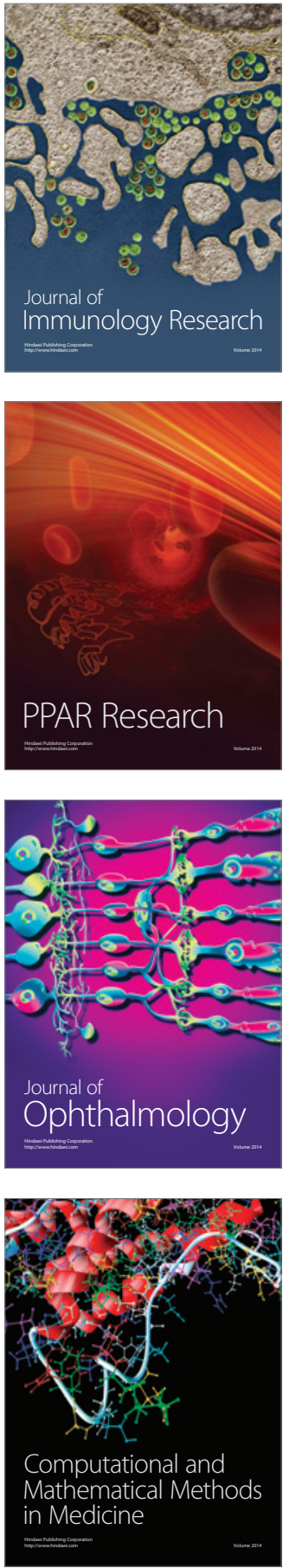

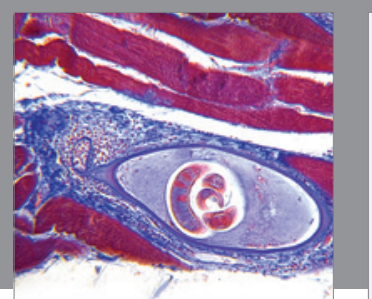

Gastroenterology Research and Practice

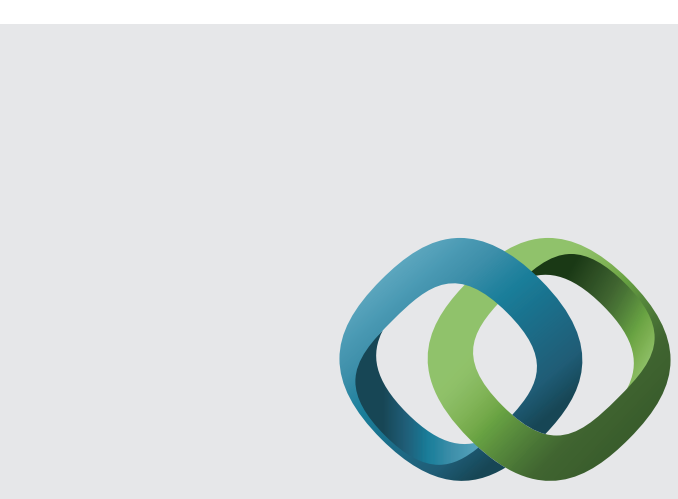

\section{Hindawi}

Submit your manuscripts at

http://www.hindawi.com
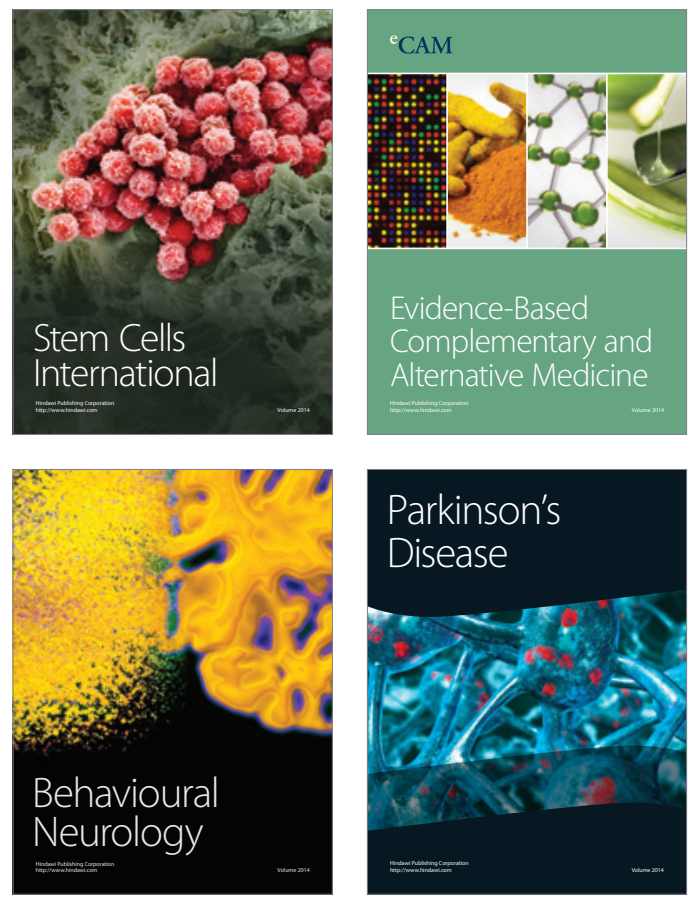
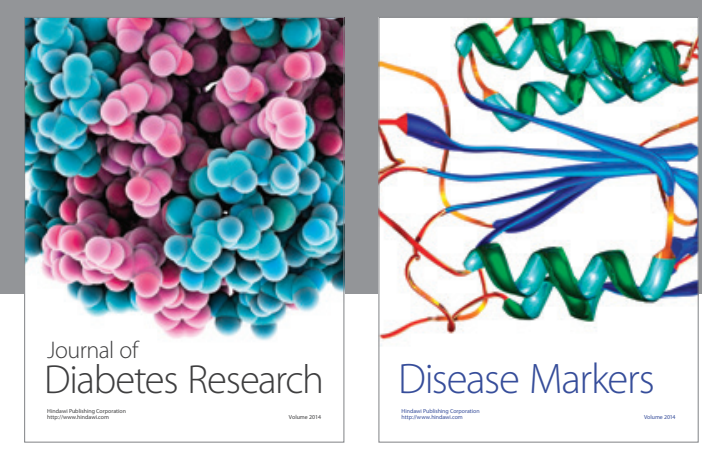

Disease Markers
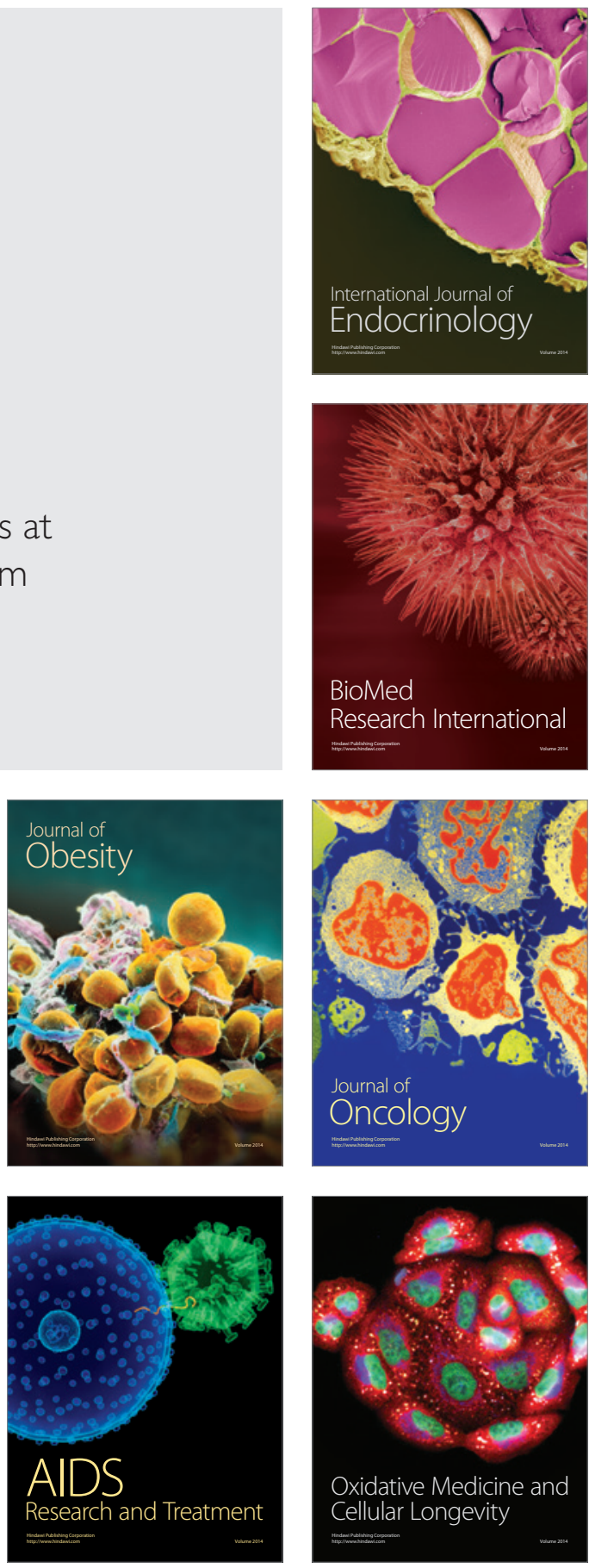